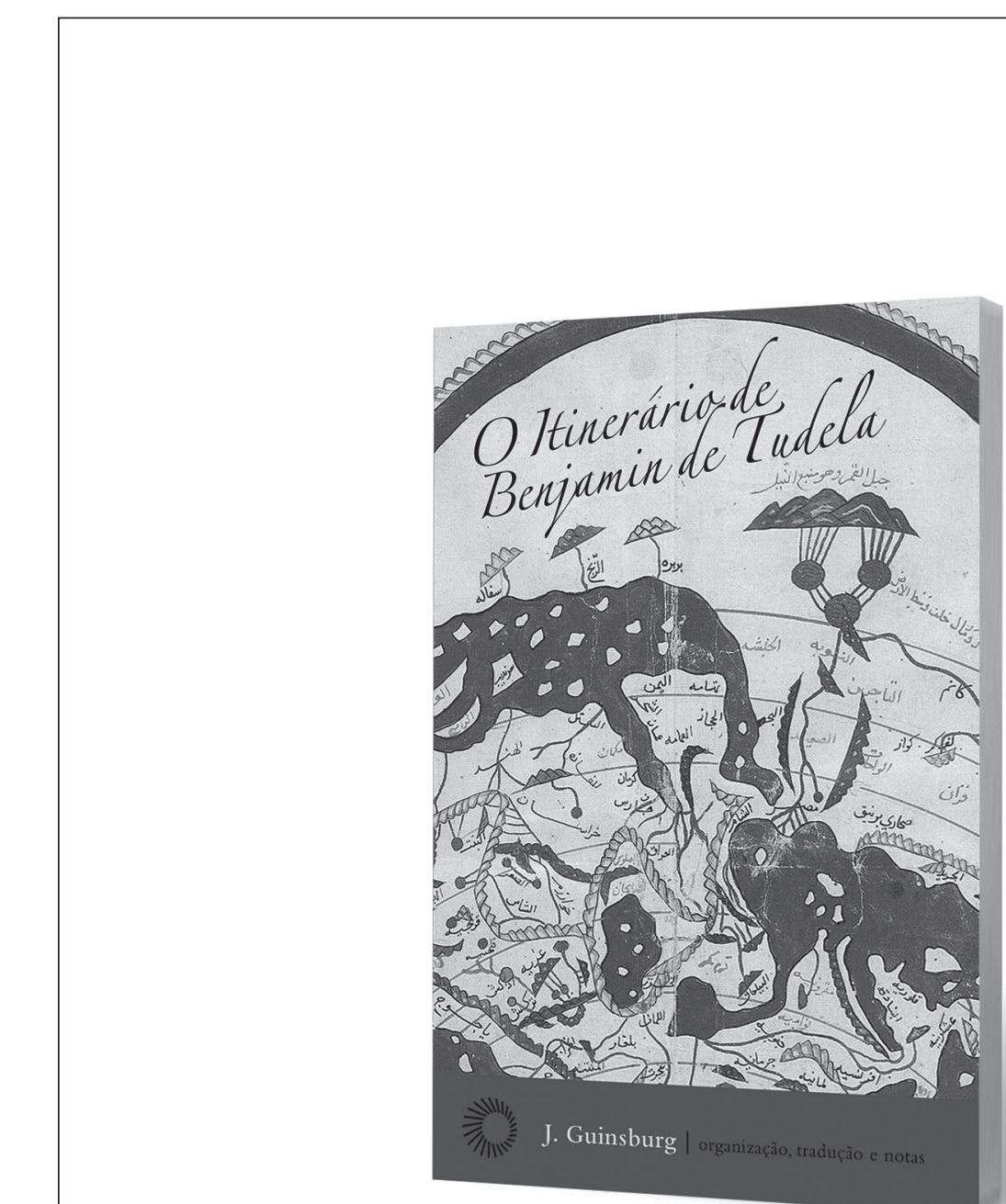

\title{
Os primórdios da geografia como ciência
}

\section{Magali Gomes Nogueira}

O Itinerário de Benjamin de Tudela, de J. Guinsburg,

São Paulo, Perspectiva, 2017, 160 pp. 


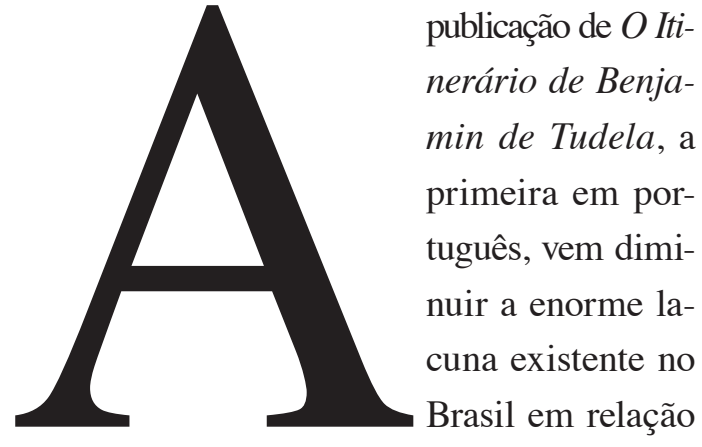

à edição crítica de textos medievais, principalmente no que toca à produção hebraica relacionada com a construção da representação do espaço medieval e o desenho do mapa-múndi tal como o conhecemos hoje. O histórico desta publicação tem como fonte principal um texto manuscrito, datado do início do século XIII, com introdução que identifica o autor como Benjamin de Tudela, atualmente em arquivo do Museu Britânico, base das primeiras edições impressas do texto: a de 1543, feita em Constantinopla por Eliezer Ben Gerschon, e a de 1575, em hebraico, pela oficina de Christophori Plantini, em Antuérpia que irá alcançar grande sucesso de vendas principalmente pela beleza de suas ilustrações. A edição que ora $\mathrm{J}$. Guinsburg apresenta e traduz para o público brasileiro realiza uma síntese entre as notas e comentários da publicação em alemão de A. Asher, 1840 e 1841, que traduz e publica a edição flamenga acima mencionada, e a de Marcus N. Adler, que, em 1907, a reedita com atualizações para a língua inglesa.

Em sua edição, Asher, preocupado com a história das ciências, apresenta o texto de Benjamin como elemento importante para a história da geografia medieval, pois possibilita "resgatar uma concepção de espaço construída por relatos de viajantes"1, entendendo por viajantes todos os que se locomoviam entre o Oriente e o Ocidente, seja com propósitos religiosos, comerciais ou de conquista e observação, movimentos bastante entrelaçados nos séculos XII e XIII. Adler, por sua vez, prioriza a questão reli-

1 As citações deste parágrafo foram retiradas da apresentação que J. Guinsburg faz da obra em sua edição.

MAGALI GOMES NOGUEIRA é doutora pelo Departamento de Geografia da FFLCH-USP. 
giosa e apresenta o texto como sendo fruto da "luta entre o Crescente e a Cruz", entendendo, porém, este movimento entre árabes e latinos como responsável pelo avanço científico ocorrido no período que classifica como "Idade de Ouro da produção hebraica medieval" pela tradução e atualização do conhecimento herdado dos antigos. Guinsburg, acompanhando Asher, destaca o importante papel das "crônicas dos viajantes que desenharam no mundo medieval o mapa-múndi das terras conhecidas", destacando o caráter tanto literário como científico dessa produção tão comum ao período.

Sem dúvida, outro exemplar famoso deste gênero é o Itinerário de Peutinger ${ }^{2}$, também conhecido como Tabula Peutinger, construído e constantemente atualizado durante os séculos de expansão do Império Romano, com uma função prática de visualizar os territórios dominados e o estabelecimento de estradas e novas cidades que ampliassem as possibilidades de domínio, administração e integração comercial entre as partes do império. Sua importância se mantém ao longo de toda a Idade Média, como comprovam as constantes cópias e atualizações.

Ambos os itinerários, realizados praticamente no mesmo espaço geográfico, separados por um tempo de mil anos, contribuíram de formas diferentes e complementares para o desenho do mapa-múndi medieval. Benjamin descreve, estabelece distâncias, limites e medidas: dias de jornada, às vezes jornadas marítimas, quadrantes, metros cúbicos, parassangas (medida persa), mi-

2 Tabula Peutingeriana. Mais de seis metros de comprimento por $30 \mathrm{~cm}$ de largura. A Tabula que conhecemos é uma cópia feita em 1265 de um original romano que sofreu muitos acréscimos ao longo dos séculos. lhas, geralmente quando associadas à circunferência de territórios, entendidos estes como reinos e/ou conjunto de cidades sob a mesma soberania. O segundo, dentro de alguma lógica projetista, coloca em um suporte plano ícones e imagens visualizando fatos e lendas em uma situação solucionada geometricamente a partir de medidas, limites e acidentes geográficos como montanhas, golfos e rios, estabelecendo relevos, moradias e economias. Por entre as imagens, episódios retirados dos diários ajudam a compor o espaço geográfico concebido pelos desenhistas do mundo medieval.

Os diários usados para compor o Itinerário de Peutinger foram coletados durante um longo período entre os séculos II a.C. e II d.C., período em que Estrabão também está compondo sua Geografia, que, por sua vez, será a base da Geografia de Ptolomeu, no século II d.C. E que, após as intervenções árabes do século IX, reaparece atualizado no final da Idade Média como Itinerário Pictum (Itinerário Ilustrado). Ptolomeu, quando recebeu a Geografia de Estrabão, reclamou da diversidade e imprecisão das medidas, da não consideração quanto a se o dia de jornada foi feito em terreno plano ou montanhoso. Essa dificuldade levará Ptolomeu a reforçar o uso da geometria como método e medida unificadora para a confecção de suas "imagens da Terra": reduzidas a uma circunferência de $360^{\circ}$, quadriculadas em latitude e longitude, os locais terrestres assinalados de acordo com as medições astronômicas convertidas em graus. Para ele, este seria o papel da geografia, que, aliada à corografia, com seus desenhos parciais e descrições culturais, comerciais e religiosas dos habitantes locais, completa a imagem do mundo conhecido. A união da palavra 
com a imagem criando coerência entre o experimentado e o transmitido.

Os diários, por sua vez, possuem diferenças de enfoque de acordo com a especialidade de seu autor. Os diários de bordo do período em que Benjamin realizou sua viagem, por exemplo, ficaram conhecidos como Diários Portulanos, por marcarem as distâncias entre portos, produtos que entram e saem dos navios, acidentes e incidentes possíveis durante a viagem e pela formação de um vocabulário novo, resultado de produtos e palavras inexistentes no vocábulo do autor do diário, provavelmente um sábio que se guiará pelas estrelas e por elas conduzirá o trajeto. O trabalho de comprovação das localizações e das distâncias entre os pontos selecionados extrapola as condições de descrição dos viajantes em geral e entra para a área das ciências naturais de então - a astronomia, a matemática, a geometria -, criando a necessidade de que as viagens fossem acompanhadas por estudiosos que pudessem ler instrumentos astronômicos e realizar conversões matemáticas, conforme determina o método ptolomaico.

Essa produção literária deixou fértil material das e para as comunidades de saber. Benjamin produziu um texto relatando o que viu e ouviu durante o período em que esteve fora de casa, por volta de 1159 a 1173. Pertencente a uma comunidade judaica, seus relatos têm sentido particularmente especial para a compreensão das atividades exercidas pelos componentes dessa comunidade espalhados por toda a Europa ocidental, adentrando no mundo asiático que, segundo ele, começava em Chipre. Vários pontos poderiam ser destacados desta narrativa para corroborar a afirmação de que os diários contribuíram para a apreensão e produção da "imagem do mundo", como, por exemplo, o contato que Benjamin teve com Abraham Ibn Ezra, importante rabino do século XII, também de Tudela, que, após anos discutindo os fundamentos hebraicos, parte em viagem com o objetivo de atualizar tábuas e refazer medições astronômicas. Juntamente com estudiosos latinos do norte da França e das Ilhas Britânicas, realiza traduções de obras de Aristóteles e de Ptolomeu, acrescidas das observações dos estudiosos de Bagdá, escritas em árabe ou hebraico. É importante destacar que esse estudioso hebreu, em seu texto El Libro de los Fundamentos de las Tablas Astronómi$c a s^{3}$, menciona a Geografia de Ptolomeu, cita dela coordenadas de algumas cidades e mostra a necessidade de sua correção a partir da utilização de instrumentos mais precisos, para obter uma imagem mais realista das terras conhecidas, comprovando a utilização dessa obra pelos estudiosos da época, bem antes da tradução de Jacob Angeli da Scarpia, feita em 1406.

O material produzido por esse grupo de estudiosos dos séculos XII e XIII, revisando as tábuas astronômicas anteriores, encontra-se documentado, no século XIV, em mãos da comunidade judaica produtora de uma "imagem do mundo" convencionalmente conhecida como padrão portulano, na verdade, o globo rendilhado em 32 direções, o que permitiria uma precisão maior na localização dos pontos terrestres e territórios, utilizando-se das ciências naturais, além de vários dados extraídos dos

3 R. Abraham Ibn Ezra. El Libro de los Fundamentos de las Tablas Astronómicas. Edição crítica, introdução e notas de José María Millás Vallicrosa. Madri/Barcelona, Consejo Superior de Investigaciones Científicas, 1947. 
diários quanto às pessoas que povoam as regiões mapeadas. Essa produção cartográfica, que expande a "imagem do mundo" em direção ao Atlântico, tem, entre seus exemplares, o Manuscrito Espagnol 30, o famoso Atlas Catalão, do judeu maiorquino Cresques Abraham. O diário de Benjamin corrobora a história dessa produção na medida em que atesta a presença da família Benevistes na cidade de Posquieres, no Sul da França, juntamente com Ibn Ezra. Essa família, provavelmente expulsa de Paris no final do século XI, se deslocará em direção à Maiorca, compondo a família de Cresques Abraham. Sem dúvida, o Itinerário contribuiu de forma decisiva para a apreensão de uma concepção de mundo cuja imagem é composta ptolomaicamente, buscando uma precisão matemática aliada a dados socioeconômicos e culturais de suas gentes. Um retrato o mais próximo possível da realidade, tendência humanista que começa a se impor à sociedade medieval.

A edição do texto de Benjamin de Tudela contribui para a compreensão dos primórdios da geografia como ciência, antes da expansão marítima, por isso mesmo teria sido importante incluir mapas produzidos contemporaneamente às peregrinações de Tudela. A utilização de imagens não referentes ao período e a não catalogação correta delas, por vezes, criam uma fantasia histórica que não corresponde à realidade geográfica medieval. 